\title{
Ultrasonic-assisted Ethanol Extraction of Bioactive Substance from Clinacanthus nutans
}

\author{
Qun YU ${ }^{1, a}$, Zhen-Hua DUAN ${ }^{1,2^{*}, \mathrm{~b}}$, Bing LIU ${ }^{1, \mathrm{a}}$, Wei-Wen DUAN ${ }^{2, \mathrm{~b}}$ and Yan LIU ${ }^{2, \mathrm{~b}}$ \\ ${ }^{1}$ College of Food Science, Hainan University, Haikou 570228, China \\ ${ }^{2}$ Institue of Food Research, Hezhou University, Hezhou 542899, China \\ ayuqun930115@163.com, bdzh65@163.com \\ *Corresponding author at: Tel:13181880391; E-mail: yuqun930115@163.com; dzh65@163.com
}

Keywords: Clinacanthus nutans, Bioactive substance, Ultrasonic-assisted ethanol extraction, Yield.

\begin{abstract}
Polyphenols, flavonoids, triterpenoid and VitaminC from Clinacanthus nutans were extracted by ultrasonic-assisted ethanol extraction. The optimal extracting conditions were established as ethanol as solvent, ultrasound treatment time 35min, solid-liquid ratio 1:45 (g/ml), ethanol concentration $70 \%$ and ultrasound power $90 \mathrm{~W}$. Results revealed that ultrasound treatment time exert a significant effect on polyphenols and flavonoids, whereas ethanol concentration plays a key role in the extraction of triterpenoid and VitaminC. Under these conditions: polyphenols $8.555 \mathrm{mg} / \mathrm{g}$, flavonoids $39.567 \mathrm{mg} / \mathrm{g}$, triterpenoid $15.216 \mathrm{mg} / \mathrm{g}$, vitaminC $0.606 \mathrm{mg} / \mathrm{g}$. This study shows that ultrasonic-assisted ethanol extraction is an efficient technology to extract bioactive substances from Clinacanthus nutans could potentially be a resource for natural antioxidants.
\end{abstract}

\section{Introduction}

Clinacanthus nutans, a member of Acanthaceae family, commonly called Torsional order flowers or The Green Arrow[1], is a magnificant herbaceous plant which originates from Malaysia and Java[2]. List of Medicinal Plants in Guangxi says that Clinacanthus nutans has effect on clearing heat, diuresis detumescence with wet, invigorating the circulation of hydrophobic, clearing moisture, and anti-tumor[3]. According to the survey, more than 75.33 hectares (Maoyang Town in Wuzhishan and Shuiman town 42hectares, Baoting town and Maogan town 16.67hectares, Lingshui County Wenluo town 8.33hectares, Qiongzhong Country Hongmao town 5hectares) of Clinacanthus nutans has been planted in Hainan province. In recent years, it's popular in Southeast Asia. It's reported that the Malaysian local cancer patients find that eating Clinacanthus nutans have antitumor effect on body. It attracts medical researchers all over the world and a series of research on it are ongoing[4]. Studies have shown that the Clinacanthus nutans is a kind of wild vegetable, which has a high nutritional value and medicinal value[5]. This is because that Clinacanthus nutans contains abundant bioactive substances: extensive sterols, polyphenols, flavonoids, triterpene glycoside and sulfur compounds, and so on[6,7]. So it's significant to extract them from Clinacanthus nutans.

Microwave-assisted Extraction is an efficient technology to extract bioactive substances from Clinacanthus nutans[8], while the aim of this study is to optimize the process of extracting the bioactive substances from Clinacanthus nutans by ultrasonic-assisted ethanol extraction. The cavitation of ultrasonic wave was utilized and to realize the extraction under the conditions of low temperature and atmospheric pressure[9]. Various parameters of the method were studied including ultrasound treatment time, solid-liquid ratio, ethanol concentration and ultrasound power. The optimal extracting conditions have been determined to provide a reference for the further development and utilization of Clinacanthus nutans.

\section{Materials and Methods}

\subsection{Materials and Chemicals}

Clinacanthus nutans powder: Wuzhishan Wanjiabao science and technology company limited in 
Hainan; Gallic acid standard, Rutin standard, Oleanolic acid, Vanillic aldehyde: Yuanye biological science and technology company limited in Shanghai; the Forint phenol standard: Suolaibao science and technology company limited in Beijing; Others' pure is analytical; The water is distilled water.

\subsection{Instruments Preparation}

KS-300E ultrasonic machine: Kesheng instrument company in Ningbo; 7200 visible spectrophotometer: Longnike equipment company limited in Shanghai; BS124S electronic scales: Sartorius company; HH-S26S electric-heated thermostatic water bath: Dadi automation instrument company in Jintan; TDZ5-WS pipe rack automatic balance centrifuge: Xiangyi laboratory instrument development company limited in Hunan.

\subsection{Methods}

\subsubsection{Determination Method of the Polyphenols Yield}

The method to determine the yield of polyphenols was according to Xu's[10] with some modifications. $20 \mathrm{mg}$ gallic acid was dissolved into a $200 \mathrm{~mL}$ volumetric flask with distilled water to be stock solution. $0.0,0.1,0.2,0.3,0.4$ and $0.5 \mathrm{~mL}$ stock solution were moved to another vitro and diluted with water into $0.5 \mathrm{~mL}$. Add $10 \% \mathrm{FC}$ reagent $2.5 \mathrm{~mL}$ and shake completely. After $5 \mathrm{~min} 7.5 \%$ $\mathrm{NaCO}_{3}$ is added in it. Fetch it into Water bath pot for $5 \mathrm{~min}$ under $50^{\circ} \mathrm{C}$. Keep it in dark place for $1 \mathrm{~h}$ at room temperature. The adsorption of different samples were measured by UV spectrophotometer at 760nm. Standard curve of polyphenols can be obtained, as follows:

$$
\mathrm{A}=91.406 \mathrm{C}_{1}+0.0159, \mathrm{r}^{2}=0.9958 \text {. }
$$

In accordance with the above standard curve measuring method, $0.5 \mathrm{~mL}$ extracting solution was moved into the colorimetric wareand the absorbance was measured by UV spectrophotometer. The polyphenols concentration was obtained by Eq.1.

Polyphenols yield $(\mathrm{mg} / \mathrm{g})=100 \mathrm{C}_{1} \times \mathrm{V}_{1} / \mathrm{m}\left(\mathrm{C}_{1}\right.$ : the quality concentration of the polyphenols, $\mathrm{V}_{1}$ : the volume of fluid under test, $\mathrm{m}$ : the qualityof Clinacanthus nutans).

\subsubsection{Determination Method of the Flavonoids Yield}

The method to determine the yield of flavonoids was according to Li's[11] with some modifications. $0.0,0.5,1.0,2.0,3.0,4.0,5.0 \mathrm{~mL}$ Rutin were moved into the volumetric flasks respectively. $0.3 \mathrm{~mL} 5 \%$ sodium nitrite solution was added in it, shaked completely and standed for $6 \mathrm{~min}$. Then add $10 \%$ aluminum nitrate solution $0.3 \mathrm{~mL}$, shake completely and stand for $6 \mathrm{~min}$. $4 \mathrm{~mL} 4 \%$ sodium hydroxide solution was moved in it and diluted with $60 \%$ ethanol into $10 \mathrm{~mL}$. Stand for $12 \mathrm{~min}$. The adsorption of different samples were measured by UV spectrophotometer at $510 \mathrm{~nm}$. Standard curve of flavonoids can be obtained, as follows:

$$
\mathrm{A}=5.8766 \mathrm{C}_{2}+0.0159, \mathrm{r}^{2}=0.9955 \text {. }
$$

In accordance with the above standard curve measuring method, $1 \mathrm{~mL}$ extracting solution was moved into the colorimetric wareand the absorbance was measured by UV spectrophotometer. The flavonoids concentration was obtained by Eq.2.

Flavonoids yield $(\mathrm{mg} / \mathrm{g})=100 \mathrm{C}_{2} \times \mathrm{V}_{2} / \mathrm{m}\left(\mathrm{C}_{2}\right.$ : the quality concentration of the flavonoids, $\mathrm{V}_{2}$ : the volume of fluid under test, $\mathrm{m}$ : the qualityof Clinacanthus nutans).

\subsubsection{Determination Method of the Triterpenoid Yield}

The method to determine the yield of triterpenoid was according to Huang's[12] with some modifications. $17 \mathrm{mg}$ Oleanolic acid was moved into volumetric flask accurately. $0.1,0.2,0.3,0.4$, 0.5, $0.6 \mathrm{~mL}$ standard solution were dissolved into vitros respectively with anhydrous ethanol to $1 \mathrm{~mL}$. $1 \mathrm{~mL}$ anhydrous ethanol was added into the blank sample. All the vitros were put in a boiling water bath until the solvent volatile completely. $5 \%$ vanillin-ice acetic acid $0.4 \mathrm{~mL}$, perchlorate $1.6 \mathrm{~mL}$ were moved in it respectively and blended quickly. Afterwards $70^{\circ} \mathrm{C}$ water bath for $15 \mathrm{~min}$, cool it to the room temperature with ice water. After $8 \mathrm{~mL}$ ethyl acetate was added, the adsorption of 
different samples were measured by UV spectrophotometer at 560nm. Standard curve of triterpenoid can be obtained, as follows:

$$
\mathrm{A}=42.899 \mathrm{C}_{3}-0.0162, \mathrm{r}^{2}=0.9958 \text {. }
$$

In accordance with the above standard curve measuring method, $0.5 \mathrm{~mL}$ extracting solution was moved into the colorimetric wareand the absorbance was measured by UV spectrophotometer. The triterpenoid concentration was obtained by Eq.3.

Triterpenoid yield $(\mathrm{mg} / \mathrm{g})=100 \mathrm{C}_{3} \times \mathrm{V}_{3} / \mathrm{m}\left(\mathrm{C}_{3}\right.$ : the quality concentration of the triterpenoid, $\mathrm{V}_{3}$ : the volume of fluid under test, $\mathrm{m}$ : the qualityof Clinacanthus nutans).

\subsubsection{Determination Method of the Vitamin C Yield}

The method to determine the yield of VitaminC was according to Zhao's[13] with some modifications. $0.2 \mathrm{mg} / \mathrm{mL}$ 2,6-dichloro indophenol solution was stored at $4^{\circ} \mathrm{C}$. It was calibrated by $0.05 \mathrm{mg} / \mathrm{mL}$ ascorbic acid solution ( it was prepared by $2 \%$ oxalic acid) before each using it. The titer was calculated by Eq.4:

$$
\mathrm{T}=\mathrm{CV} /\left(\mathrm{V}_{1}-\mathrm{V}_{0}\right)
$$

$\mathrm{C}$ : concentration of standard ascorbic acid, $\mathrm{V}$ : the volume of standard ascorbic acid solution that have taken, $\mathrm{V}_{0}$ : the volume of 2,6-dichloro indophenol that the blank solution consumed, $\mathrm{V}_{1}$ : the volume of 2,6-dichloro indophenol that the titration consumed.

$10 \mathrm{~mL}$ extracting solution was moved into conical flask and titrated by 2,6-dichloro indophenol. Write down the consumed volume. Vitamin C (mg/100mg) yield was calculated according to Eq.5:

$$
\mathrm{VC}(\mathrm{mg} / 100 \mathrm{mg})=5\left(\mathrm{~V}_{2}-\mathrm{V}_{0}\right) \mathrm{T} / \mathrm{M}
$$

$\mathrm{V}_{0}$ : volume of 2,6-dichloro indophenol that the blank solution consumed, $\mathrm{mL} ; \mathrm{V}_{2}$ : the volume of 2,6-dichloro indophenol that the titration consumed, $\mathrm{mL}$; $\mathrm{T}$ : the titer, $\mathrm{mg} / \mathrm{mL}$; $\mathrm{M}$ : the quality of Clinacanthus nutans,g.

\subsubsection{Design of Extraction Test}

The single factor test: according to the results of preliminary experiments, ultrasound treatment time(10min,20min,30min,40min,50min), solid-liquid ratio(1:20, 1:30, 1:40, 1:50, 1:60), ethanol concentration(20\%,40\%,60\%,80\%,100\%) and ultrasound power(72W, 108W, 144W, 180W, 216W) were elected to the factors of the single factor test. Under the condition that other factors are invariable, make a research on every factor's influence on the yield of polyphenols, flavonoids, triterpenoid and VC from Clinacanthus nutans.

Orthogonal test: based on the result of the single factor test, process of ultrasonic-assisted extraction is optimized by the orthogonal experiment. The design of factors and levels is shown in Table1.

Table1 Factors and their levels in orthogonal array design

\begin{tabular}{|c|c|c|c|c|}
\hline \multirow{2}{*}{ level } & \multicolumn{4}{|c|}{ factor } \\
\cline { 2 - 5 } & $\begin{array}{c}\text { A } \\
\text { ultrasound } \\
\text { time/min }\end{array}$ & $\begin{array}{c}\text { B } \\
\text { solid-liquid } \\
\text { ratio }\end{array}$ & $\begin{array}{c}\text { C } \\
\text { Ethanol } \\
\text { concentration/\% }\end{array}$ & $\begin{array}{c}\text { D } \\
\text { ultrasound } \\
\text { power/W }\end{array}$ \\
\hline 1 & 35 & $1: 35$ & 50 & 90 \\
\hline 2 & 40 & $1: 40$ & 60 & 108 \\
\hline 3 & 45 & $1: 45$ & 70 & 126 \\
\hline
\end{tabular}




\section{Results and Discussion}

\subsection{Effect of Ultrasound Treatment Time on Yield}

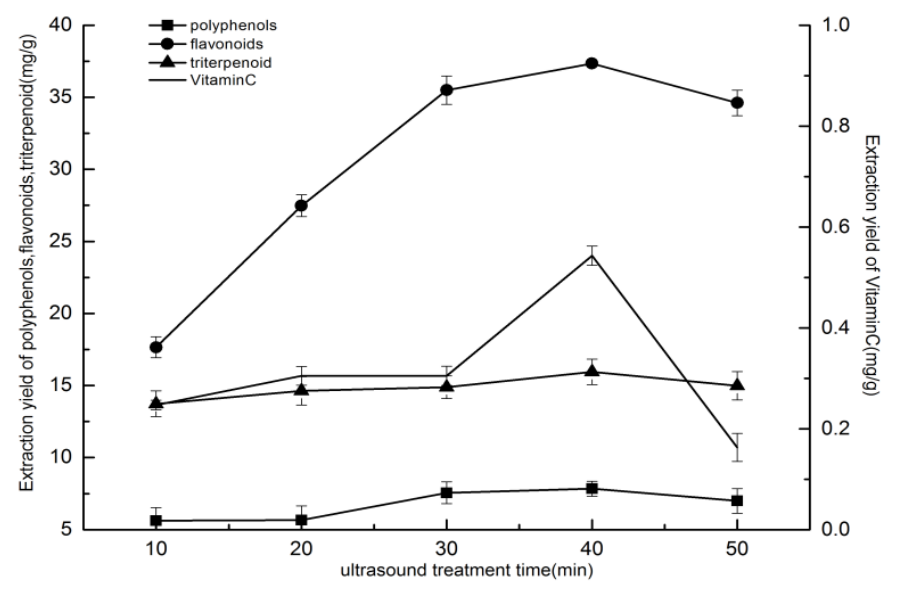

Fig.1 Effect of ultrasound treatment time on yield

The effect of ultrasound treatment time on yields of polyphenols, flavonoids, triterpenoid and VitaminC was evaluated. The rest of the variables were a solid-liquid ratio of 1:40 g/mL, ethanol concentration of $60 \%$ and ultrasound power of $144 \mathrm{~W}$. The yields of bioactive substances after various extractions are shown in Fig.1. It was observed that 40min of ultrasound treatment time can increase the yields and prolonged irradiation led to a reduction in yields. The highest yield was obtained after 144W for 40min's extraction. Because the longer time will promote the spread of bioactive substances, but overlong time will destruct the molecular structure of bioactive substances, so that the yield of the four bioactive substances decreased[14]. Time played an important role on the yields. Among them, triterpenoid and polyphenols changed gently during this process; the yield of VC and flavonoids changed obviously. Different bioactive substance present different trend. This phenomenon is relevant with their molecular structure. Thus, 40min was deemed as the optimal ultrasound treatment time.

\subsection{Effect of Material/Liquid Radio on Yield}

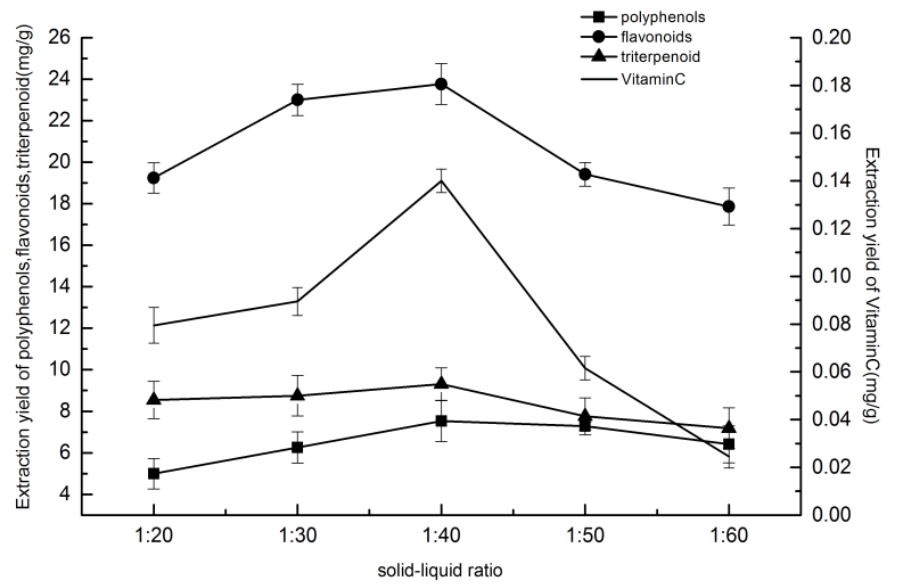

Fig.2 Effect of material/liquid radio on yield

Solid-liquid ratio is an important factor in separation technique. To avoid inadequate extraction, the effect of solid-liquid ratio on the yields of polyphenols, flavonoids, triterpenoid and VitaminC were studied with different solid-liquid ratios under a ultrasound power of $144 \mathrm{~W}$, ethanol concentration of $60 \%$ and an extraction time of $40 \mathrm{~min}$. In Fig.2, the yields of bioactive substances increased 
dramatically with the increasing of solid-liquid ratios from 1:20 to $1: 40 \mathrm{~g} / \mathrm{mL}$, the yield was the highest when solid-liquid ratio was $1: 40 \mathrm{~g} / \mathrm{mL}$; while solid-liquid ratios were higher than 1:40g/mL, high solid-liquid ratios bright a decrease of their yields. Suitable solid-liquid ratio can make Clinacanthus nutans dissolve completely. When solid- liquid ratio was 1:50 g/mL, the yield decreased obviously. This is because that the solvent molecules share more energy[15]. Among them, VC and flavonoids changed obviously during this process. Excessive solid-liquid ratio is bad for deconperssion concentration. Thus, taking the consumption of solvent into account, the solid-liquid ratio in present test was identified as 1:40 g/mL.

\subsection{Effect of Ethanol Concentration on Yield}

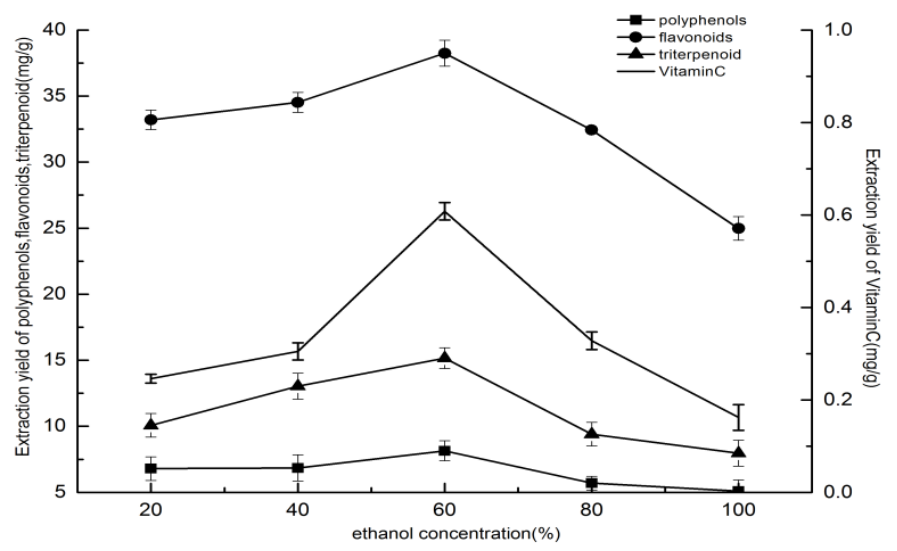

Fig.3 Effect of ethanol concentration on yield

The effect of ethanol concentration on yields of polyphenols, flavonoids, triterpenoid and VitaminC was evaluated. The rest of the variables were a solid-liquid ratio of 1:40 g/mL, every extraction cycle of $40 \mathrm{~min}$ and ultrasound power of $144 \mathrm{~W}$. Fig.3 shows that as the ethanol concentration increased, the yields of bioactive ingredients were gradually enhanced. The highest yield was obtained when the ethanol concentration is $60 \%$. While excessive concentration of ethanol lead to the a reduction in yields. This is perhaps because that the solubility of biological macromolecules such as protein decreased, blocking the microporous of organization and it increases the mass transfer resistance of tissue cells and extraction solvent[16]. During the process, the blockage effect of biological macromolecules on flavonoids and vitamin $C$ is more obvious. This phenomenon is relevant with their molecular structure. The nature of the material is decided by the structure of the material. Therefore, it was appropriate to select $60 \%$ as the practical ethanol concentration.

\subsection{Effect of Ultrasound Power on Yield}

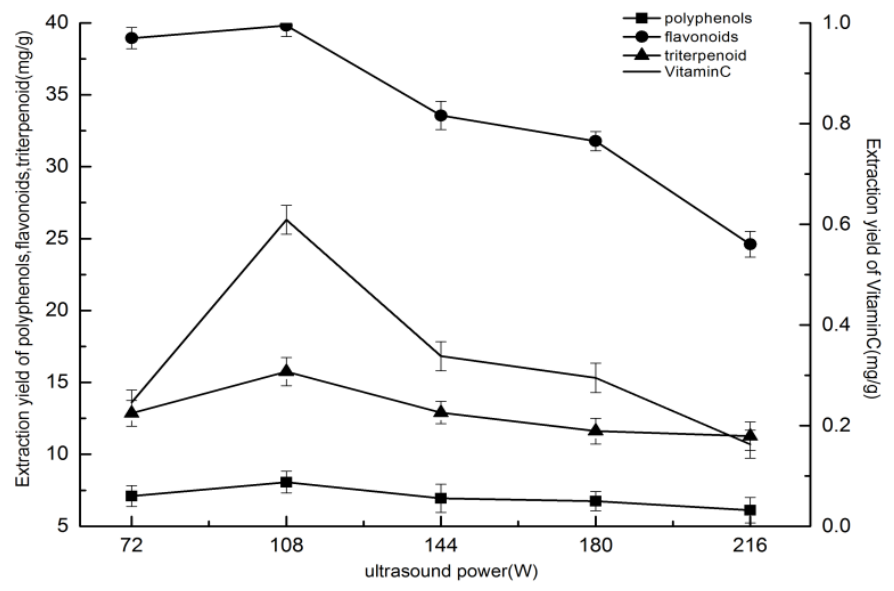

Fig.4 Effect of ultrasound power on yield 
The effect of ultrasound power on yields of polyphenols, flavonoids, triterpenoid and VitaminC was evaluated. The rest of the variables were a solid-liquid ratio of 1:40 g/mL, ethanol concentration of $60 \%$ and extraction cycle of $40 \mathrm{~min}$ each. Fig.4 showed that as the power increased, the yields of bioactive ingredients were gradually enhanced. This is perhaps because that ultrasound power become higher, the material can absorb more ultrasound energy, which increases damage of the sample cell and is good for leaching the active ingredients. However, when the ultrasound power was more than $108 \mathrm{~W}$, the yields showed a declining trend. This fact can be attributed to the power increase of moisture content in the sample destroy the bioactive substances and dissolution of impurities[17]. In a word, the ultrasound power in present test was identified as 108W.

\subsection{Results and Discussion of Orthogonal Test}

Orthogonal experimental design was employed to optimize the ultrasonic-assisted extraction process of polyphenols, flavonoids, triterpenoid and VitaminC, and the results are shown in Table 2. It shows that ultrasound treatment time is the most significant factor while ethanol concentration is the insignificant for the polyphenols yield, in an order of $\mathrm{A}>\mathrm{D}>\mathrm{B}>\mathrm{C}$, and the optimal level is $A_{1} B_{3} C_{3} D_{2}$; ultrasound treatment time is the most significant factor while ethanol concentration is the insignificant for the flavonoids yield, in an order of $A>D>B>C$, and the optimal level is $A_{1} B_{3} C_{2} D_{1}$; ethanol concentration is the most significant factor while ultrasound power is the insignificant for the triterpenoid yield, in an order $C>A>B>D$, and the optimal level is $A_{1} B_{2} C_{3} D_{3}$; ethanol concentration is the most significant factor while ultrasound treatment time is the insignificant for the VitaminC yield, in an order of $C>B>D>A$, and the optimal level is $A_{2} B_{3} C_{3} D_{3}$. Considering that ultrasound treatment time is the most significant influence on polyphenols and flavonoids, so the best ultrasound treatment time $35 \mathrm{~min}$ of polyphenols and flavonoids is elected as the optimal ultrasound treatment time; solid-liquid ratio is the most significant influence on the four kinds of bioactive substances, considering saving the raw materials, the best solid-liquid ratio 1:45 is elected as the optimal solid-liquid ratio; ethanol concentration is the most significant influence on triterpenoid and VitaminC, so the best ethanol concentration $70 \%$ of triterpenoid and VitaminC is elected as the optimal ethanol concentration; ultrasound power is significant influence on polyphenols and flavonoids, in order to ensure the maximum activity, $90 \mathrm{~W}$ is elected as the optimal ultrasound power. According to this experimental design, the optimum conditions for ultrasonic-assisted extraction of polyphenols, flavonoids, triterpenoid and VitaminC from Clinacanthus nutans are that ultrasound treatment time of $35 \mathrm{~min}$, solid-liquid ratio of 1:45 g/mL, ethanol concentration of $70 \%$ and ultrasound power of $90 \mathrm{~W}$.

Table2 Results of orthogonal test

\begin{tabular}{|c|c|c|c|c|c|c|c|c|}
\hline No. & A & $\mathbf{B}$ & C & $\mathbf{D}$ & $\begin{array}{c}\text { Polyphenols } \\
\text { (mg/g) }\end{array}$ & $\begin{array}{c}\text { flavonoid } \\
\text { s } \\
(\mathrm{mg} / \mathrm{g}) \\
\end{array}$ & $\begin{array}{c}\text { triterpenoi } \\
\text { d } \\
(\mathrm{mg} / \mathrm{g})\end{array}$ & $\begin{array}{c}\text { Vitamin } \\
\text { C } \\
(\mathrm{mg} / \mathrm{g})\end{array}$ \\
\hline 1 & 1 & 1 & 1 & 1 & 7.155 & 39.596 & 12.882 & 0.337 \\
\hline 2 & 1 & 2 & 2 & 2 & 7.246 & 38.273 & 14.139 & 0.405 \\
\hline 3 & 1 & 3 & 3 & 3 & 7.829 & 38.597 & 14.772 & 0.581 \\
\hline 4 & 2 & 1 & 2 & 3 & 6.649 & 36.695 & 13.397 & 0.372 \\
\hline 5 & 2 & 2 & 3 & 1 & 6.841 & 37.479 & 14.600 & 0.569 \\
\hline 6 & 2 & 3 & 1 & 2 & 8.045 & 36.266 & 11.419 & 0.420 \\
\hline 7 & 3 & 1 & 3 & 2 & 6.540 & 32.259 & 14.032 & 0.496 \\
\hline 8 & 3 & 2 & 1 & 3 & 5.548 & 31.634 & 12.366 & 0.417 \\
\hline 9 & 3 & 3 & 2 & 1 & 5.725 & 34.627 & 12.974 & 0.415 \\
\hline \multirow{4}{*}{$\begin{array}{l}\text { polyphenols } \\
\text { (mg/g) }\end{array}$} & 7.410 & 6.781 & 6.916 & 6.574 & \multicolumn{2}{|c|}{ order } & \multicolumn{2}{|c|}{ the optimal level } \\
\hline & 7.179 & 6.545 & 6.540 & 7.277 & \multicolumn{2}{|c|}{$\mathrm{A}>\mathrm{D}>\mathrm{B}>\mathrm{C}$} & \multicolumn{2}{|c|}{$\mathrm{A}_{1} \mathrm{~B}_{3} \mathrm{C}_{3} \mathrm{D}_{2}$} \\
\hline & 5.938 & 7.200 & 7.070 & 6.675 & & & & \\
\hline & 1.472 & 0.655 & 0.530 & 0.703 & & & & \\
\hline
\end{tabular}




\begin{tabular}{|c|c|c|c|c|c|c|}
\hline No. & A & B & C & D & $\begin{array}{c}\text { Polyphenols } \\
\text { (mg/g) }\end{array}$ & $\begin{array}{c}\text { flavonoids } \\
\text { (mg/g) }\end{array}$ \\
\hline \multirow{4}{*}{$\begin{array}{l}\text { flavonoids } \\
\text { (mg/g) }\end{array}$} & 38.822 & 36.183 & 35.832 & 37.234 & order & the optimal level \\
\hline & 36.813 & 35.795 & 36.532 & 35.599 & $\mathrm{~A}>\mathrm{D}>\mathrm{B}>\mathrm{C}$ & $\mathrm{A}_{1} \mathrm{~B}_{3} \mathrm{C}_{2} \mathrm{D}_{1}$ \\
\hline & 32.843 & 36.497 & 36.112 & 35.642 & & \\
\hline & 5.979 & 0.702 & 0.700 & 1.635 & & \\
\hline \multirow{4}{*}{$\begin{array}{l}\text { triterpenoid } \\
\text { (mg/g) }\end{array}$} & 13.931 & 13.473 & 12.222 & 13.485 & order & the optimal level \\
\hline & 13.139 & 13.702 & 13.503 & 13.197 & $C>A>B>D$ & $\mathrm{~A}_{1} \mathrm{~B}_{2} \mathrm{C}_{3} \mathrm{D}_{3}$ \\
\hline & 13.124 & 13.055 & 14.468 & 13.512 & & \\
\hline & 0.792 & 0.647 & 2.246 & 0.315 & & \\
\hline \multirow{4}{*}{$\begin{array}{l}\text { VitaminC } \\
\text { (mg/g) }\end{array}$} & 0.441 & 0.402 & 0.391 & 0.440 & order & the optimal level \\
\hline & 0.454 & 0.464 & 0.397 & 0.440 & $C>B>D>A$ & $\mathrm{~A}_{2} \mathrm{~B}_{3} \mathrm{C}_{3} \mathrm{D}_{3}$ \\
\hline & 0.443 & 0.472 & 0.549 & 0.457 & & \\
\hline & 0.013 & 0.070 & 0.158 & 0.017 & & \\
\hline
\end{tabular}

Verification Test was carried out at these best conditions, and the yields of polyphenols, flavonoids, triterpenoid and VitaminC were $8.555 \mathrm{mg} / \mathrm{g}, 39.567 \mathrm{mg} / \mathrm{g}, 15.216 \mathrm{mg} / \mathrm{g}$ and $0.606 \mathrm{mg} / \mathrm{g}$, respectively, which were in good agreement with the predicted.

\section{Summary}

This study focused on the optimization of ultrasonic-assisted extraction process for bioactive substances (polyphenols, flavonoids, triterpenoid, VitaminC) from Clinacanthus nutans. The study shows that: order of the polyphenols yield is ultrasound treatment time>ultrasound power>solid-liquid ratio>ethanol concentration; order of the flavonoids yield is ultrasound treatment time> ultrasound power>solid-liquid ratio>ethanol concentration; order of the triterpenoid yield is ethanol concentration>ultrasound treatment time $>$ solid-liquid ratio $>$ ultrasound power; order of the VC yield is ethanol concentration $>$ solid-liquid ratio $>$ ultrasound power $>$ ultrasound treatment time.

According to the above experiments, the optimum ultrasonic-assisted extraction conditions were determined to be: ultrasound treatment time of $35 \mathrm{~min}$, solid-liquid ratio of $1: 45 \mathrm{~g} / \mathrm{mL}$, ethanol concentration of $70 \%$ and ultrasound power of $90 \mathrm{~W}$.

\section{Acknowledgments}

The fund of The Characteristics of GuangXi Fruits and Vegetables Processing and Preservation technology Research (No.YS201601) are acknowledged for their contribution to the experimental work.

\section{References}

[1]Ji-Tian LIN, Hui-Min LI, Jing-Guang YU. Studies about the chemical ingredients of Torsional flowers. Chinese Herbal Medicine ,1983,14 :337. (In Chinese)

[2]Bo YI, Wen-Tong XU, Dun DENG, et al. Analysis of Amino Acids, Trace Elements and Chemical Consti- tuents from the leaves of Clinacanthus nutans. Pharmaceutical Journal of Chinese People’s Liberation Army, 2012,28, (5): 396. (In Chinese)

[3]Xian-Er WANG, Xi-Wen ZHONG, Wen-Xia ZHANG, et al. The study on the chemical ingredients from Clinacanth- us nutans and analyse its antitumor effect. China Pharmacy, 2013,24(43): 4104-4107. (In Chinese)

[4]Teshima KI, Kaneko T, Ohtani K, et al. C-Glycosyl flavones from Clinacanthus nutans[J]. Nat 
Med,1997,51(6):557.

[5]Qun YU, Zhen-Hua DUAN, Wei-Wen DUAN, et al. Analysis and evaluation of nutrition composition of Clinacanthus nutans [A].Xie Liquan. Proceedings of the 2nd technical congress on resources, environment and engineering,CREE 2015[C].London: CRC Press, 2016.369-374. (In Chinese)

[6]Jia-Qi HU, Hong-Bin CUI, Zhen-Yu LI. Flora of China. In: Science press, 2002: 252-253. (In Chinese)

[7]SakdaartS, ShuyPromA, PientongC,et al. Bioaetive constituents from the leaves of Clinacanthus nutans Lindau [J]. Bioog Med Chem, 2009,17(5):1857-1860.

[8]Qun YU, Wei-Wen DUAN, Bing LIU, et al. Microwave-assisted Extraction of Bioactive Substances from Clinaca- nthus nutans. Advances in Engineering Research, 2016, 53:748-754. (In Chinese)

[9]Han-Wen LIU, Hong-Xing CHEN, Xiao-Yu GONG. Study on microwave and ultrasonic-assisted extraction of flavonoids in the sweetpotapo leaves. Science and Technology of Food Industry, 2014,16:298-301. (In Chinese)

[10]Hui-Yan XU, Xiao-Dong SUN, Pei-Jun ZHANG, et al. Determination of total polyphenols of Chinese jujube juice by Folin- Ciocaileu method. Food Research and Development, 2009,30(3): 126-128. (In Chinese)

[11]Peng-Jing LI, Xu-Guang LIU, Hai-Rong LONG, et al. Ultrasonic-assisted extraction and antioxidant activity of flavonoids from water chestnut shell. Food Science and Technology, 2011,36(01):167-171. (In Chinese)

[12]Sheng-Quan HUANG, Song-Jun YAO, Cui-Ling LIU, et al. Determination and Variation of Triterpenoids Content of Glossy ganoderma Harvested at Different Growth Periods. Modern Food Science and Technology, 2011, 27 (8):1015-1019. (In Chinese)

[13]Xiao-Mei ZHAO, Ying JIANG, Yu-Peng WU. Assay Research on VC in Fruit and Vegetable. Food Science, 2006,27(3): 197-199. (In Chinese)

[14]Xiao-Ying XIAO, Jie PANG, et al. Study on extraction of Flavonoids and antioxidant activity of the extracts from Ampelopsis grossedentata. Fu Jian, Fujian Agriculture and Forestry University. 2013,04. (In Chinese)

[15]Zhen-Hua DUAN, Ju-Lan WANG, Mei-Hua YI, et al. Recovery of Proteins from Silver carp By-products with Enzymatic Hydrolysis and Reduction of Bitterness in Hydrolysate. Journal of Food Process Engineering, 2010, 33(5):962-978. (In Chinese)

[16]Xiao-Xiang HAN, Ling-Xiao ZHOU, Jian-Rong LI, et al. Study on the ultrasonic-assisted extraction of flavonoids from Citrus Changshan-huyou and its antioxidant activity. Journal of Chinese Institute of Food Science and Technology, 2011, 11(4): 55-61. (In Chinese)

[17]Xue-Mei ZHAO, Xing-Qian YE, Yu-Fang XI. Study on the extraction of flavonoids from Citrus Changshan-huyou. Journal of Chinese Institute of Food Science and Technology, 2004, 4(2): 19-24. (In Chinese) 